\title{
Development of Two-Stage Network Data Envelopment Analysis (DEA) Model to Measure Production Line's Performance: Combination of Automation and Labor
}

\author{
${ }^{1}$ N.A.C.Azhar, ${ }^{2}$ M.A.Mansor, , ${ }^{3}$ S.A.Rusdan and ${ }^{4}$ S.N.M.Saffe \\ ${ }^{1,2,4}$ Faculty of Engineering Technology, Universiti Malaysia Pahang, Lebuhraya Tun \\ Razak, 26300, Kuantan, Pahang, Malaysia \\ ${ }^{3}$ Faculty of Creative Technology and Heritage, Universiti Malaysia Kelantan, Beg \\ Berkunci No. 1, 16300 Bachok, Kelantan, Malaysia \\ 1afiezaazhar7@gmail.com
}

\begin{abstract}
Nowadays, the growth of industry can be seen as a nature of the world. Each company race again each other to increase productivity to produce new, high quality and product that fulfil customer demand. One can achieve the Key Performance Indicator (KPI) or targeted goal but without considering the cost, manpower, time or others elements is inefficient toward productivity. Upgrade production line in manufacturing industry needs huge investment to come out with good performance. The company can receive Return of Investment (ROI) and save more money from paying labor salary and increase productivity. However, the company also may have the risk of losing their money from the investment done. In this research, we studied the effectiveness of production line that equipped with automation usage to determine the productivity and quality of the product produced. We apply Data Envelopment Analysis (DEA) to measure efficiencies of the production line where DEA is one of an excellent tool that can evaluate efficiencies and have been using widely in many sectors. The model that will be used in this study is Two-Stage Network DEA. As a case study, this research focuses on the production line that producing a product with a high and continues demand to observe how the investment on automation can give good return or otherwise.
\end{abstract}

Index Terms- Productivity, Data Envelopment Analysis (DEA), Two-Stage Network DEA, Automation and Labor

\section{INTRODUCTION}

The manufacturing industry is one of the fastest growing industry in Malaysia. This phenomenon makes company always create new changes toward a human way of work, machines demand, company mission and vision and can line up against other companies. Any changes can help the company to reduce the cost of time, the number of worker, rejection of unit, machine down (time and maintenance) and loss of customer due to customer's dissatisfaction. Furthermore, this reduces cost directly that can save the quality of the product being produced and indirectly lead the company to become one of the most well-known company among customers. Therefore, production department in the company need to be improved precisely by maintaining the productivity of product based on the quality demand and effectively control this process and bring profit to the company.

There are many weights needed to be evaluated in the manufacturing industry. Each of the weight is connected to each other to come out with high performance and high quality of the product. Using Two-stage Network DEA, the relationship between these weights can be estimated in more detail and structured. According to Rolf and Shawna [1], Two-Stage Network DEA model can be applied to a variety of situations such as intermediate products, allocations of budgets or fixed factors and certain (time-separable) dynamic systems. Almost all basic DEA models treat their Decision-Making Unit (DMU) as black boxes. The difference with networks model introduced by Rolf and Shawna [1]; the model allows the user to study organizational performance and its component performance and let them choose the DMU. 


\section{QUALITY AND PRODUCTIVITY IMPROVEMENT}

It is important for a company to understand the process involved in producing a unit of product. Understanding the process means that the company will know the production line capability and the limit of what it can do [2]. Poor understanding about the process leads the company failure to recognize the existing problem and sometimes leads the manager to apply a solution to the problem that does not exist. It is hard for the company to reach productivity and produce a high quality product. Figure 1 shows the quality improvement process that can determine the difference between actual and desired performance and then improve the production process [2]. By improving the performance without this measurement, the company may hit a few, but the score would not bring anything. The company does not know where the problem is and how to solve a problem. Introducing measurements typically improve the quality for 10 to $20 \%$ in a few weeks.

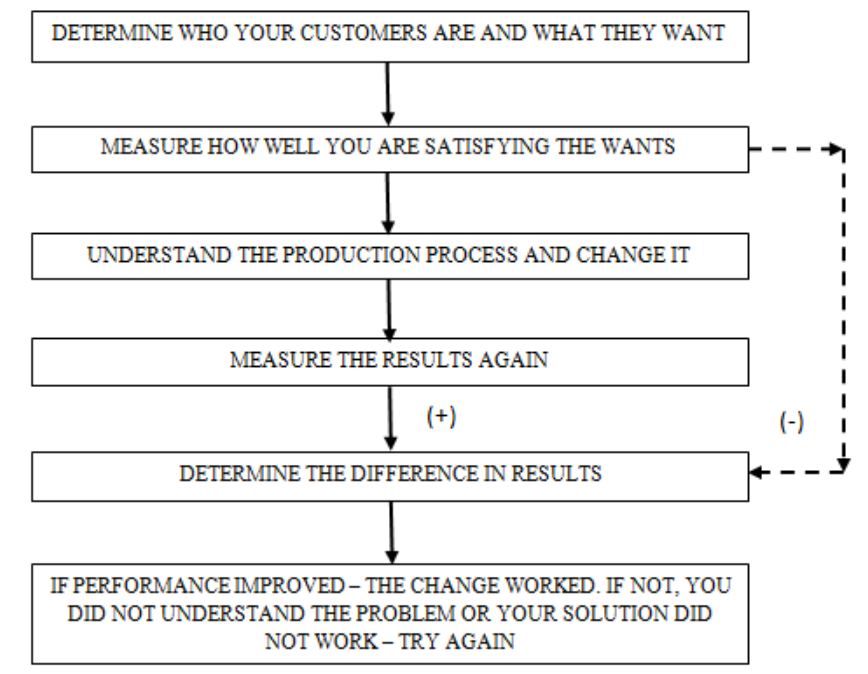

\section{Fig.1 The Quality Improvement Process (source: Kaydoss (1991))}

\section{TWO-STAGE NETWORK DEA}

DEA is widely used to evaluate the relative effectiveness and efficiency of operating units, especially in the banking industry and within the same organizational objectives by measuring the relationship between multiple inputs and outputs. Two-Stage model calculates the first stage, second stage, and the whole production process independently [3]. However, asserted that it is inappropriate to calculate the two sub-processes independently since a production process is composed of a series of two sub-processes and the intermediate products play an interactive role in both processes [4].

In recent years, a number of studies have looked at DMUs with network structures (see, e.g., [1], [4]-[8]) In a survey done before, the authors pointed out several approaches in modelling DMUs with a Two-Stage Network structure [9]. Typically, models are developed based upon additive or geometric mean efficiency decompositions. Though the Network DEA approached, this model can deal with different network structures, it cannot provide efficiency decomposition or efficiency ratings for sub-DMUs that constitute the entire network DMUs [1]. Besides that, there is others study about a network DEA model developed using slacks-based models that can evaluate both divisional and over all efficiencies of DMUs [5].

\section{DEA WINDOW ANALYSIA}

A DEA window analysis is run in order to obtain the efficiency scores. Window analysis is a DEA extended method for monitoring, planning, and improving productivity [10]. There are many researches done using window analysis, for example DEA window analysis used to estimate the 
performance of 12 Swedish bank over 1984 to 1992 [11]. DEA window analysis also had been utilizes to assess eight major container ports in Japan over 1990 to 1999 [12]. Other than that, DEA window analysis was used to identify efficiency trends over time for a semiconductor manufacturer [13].

Window analysis technique works on the principle of moving averages and is useful in detecting performance trends of a decision making unit over time[14]. Each DMU in a different period is treated as if it was a more accurate or independent DMU but remains comparable in the same window [14]. By assuming that there are $n$ DMU, which are observed in $l$ periods, thus we will have $n \times l$ "new" DMUs. Let $w$ as window width, the number of time periods are included in the analysis. The assessment then will be conducted $(l-w+1)$ in times where each assessment will calculate the efficiency of $n \times w$ DMUs.

\section{TWO-STAGE NETWORK DEA TO MEASURE PERFORMACE OF PRODUCTION LINE}

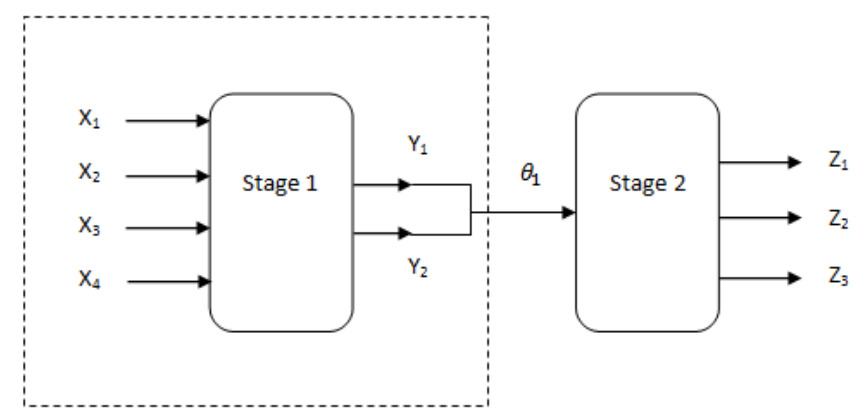

Fig.2 Two-Stage Network DEA Model for Production Line Performance

\subsection{Stage 1: Performance Evaluation of Productivity}

In stage 1 , we will have four inputs and two outputs data. To measure the production line effectiveness with and without automation, the inputs and outputs data for the evaluation must be identified and relevant. At stage 1, we had evaluated the productivity of each production line with high demand. The idea behind this model is $x_{1}$ of total working hour of $x_{2}$ labor and $x_{2}$ index of automation usage to produce $x_{4}$ product at its standard time use as the input of this stage. The outputs of this stage are $y_{1}$ of total unit produced and $y_{2}$ of total quality product. The nonautomation production line cannot be zero in DEA calculation. Index automation usage can be used to give marks of to each production line. For the index no. of automation $\left(x_{\mathrm{a}}\right)$, the ideal situation is the production line without any installation of automation. Therefore, we gave full marks (100 marks) to the production line without automation.

From stage 1 , the evaluation gives the result of $\theta_{1}$ where $\theta_{1}$ is an efficiency from ratio of index automation usage and number of labour with its standard time and the total working hour as an input to determine the productivity against the total unit and quality unit produced as output. The value $\theta_{1}$ can be used to determine the most efficient production line in terms of productivity and rank the production lines.

\subsection{Stage 2: Evaluation of Quality in Production Lines in Terms of Cost and Time.}

The measurement in-between the two stages are called intermediate measures. At stage two, we had evaluated the quality of production performance by using $\theta_{1}$ as an input. The outputs in stage 2 are $z_{1}$ index of time waste, $z_{2}$ index of cost waste and $z_{a}$ of productivity. Here we can see the connection of both stages that influence the result of this case study. From stage 1, we were only focusing on evaluation of productivity without concern on quality of the product being produced. To understand the overall performance of production line, we will use the value $\theta_{1}$ as an input in stage 2 . Using the value of $\theta_{1}$ can help us to know the quality of the product being produced in stage 2 whether it is parallel with the productivity. Here we can prove that the value of $\theta_{1}$ is excellent for the overall production line performance or only excellent in 
productivity. We want to understand the performance of each production line as if it faces any problem in producing the targeted productivity or producing the quality product.

From stage 2, the evaluation gives the result of $\theta_{2}$ where $\theta_{2}$ is an efficiency from ratio of average value of $\theta_{1}$ from each production line as an input against index of time waste, index of cost waste and productivity to determine the quality of the product being produced in terms of time and cost. The $\theta_{2}$ value can be used to determine the most efficient production line and rank it.

\section{RESULT AND DISCUSSION}

\subsection{Stage 1: Performance Evaluation of Productivity}

Initially, we evaluated stage 1 of the production's line productivity with automation and non-automation. Table 1 shows the data being organized in Window (Window-I-C) model and the inputs and outputs data to evaluate the productivity by five different production lines in 5 months. From Table 1, we can see that the data tendency of value is mixed and different from each other. For index number of automation $x_{\mathrm{a}}$, the ideal behind this situation is the production line with automation will be divided with 100 . Since the high number of automation usage is 4 , we divided 100 by 5 , which gives 1 automation usage is equal to 20 marks. The marks then are deducted from the full mark (100 marks) depending on automation usage. By using DEASolver software, we calculated the data using window analysis where the length of window is 1 and 2 to study the different performance due to period of time.

Table 1 Inputs and outputs data to evaluate productivity

\begin{tabular}{|c|c|c|c|c|c|c|}
\hline Month & DMU & $\mathrm{A}$ & $\mathrm{B}$ & $\mathrm{C}$ & $\mathrm{D}$ & $E$ \\
\hline \multirow[t]{6}{*}{1} & $x_{1}$ & 617 & 629 & 261 & 600 & 197 \\
\hline & $x_{2}$ & 6752 & 6576 & 2396 & 5962 & 2077 \\
\hline & $x_{3}$ & 197426 & 87784 & 94704 & 249456 & 54658 \\
\hline & $x_{4}$ & 60 & 80 & 100 & 100 & 100 \\
\hline & $y_{1}$ & 307501 & 103699 & 86326 & 244817 & 47024 \\
\hline & $y_{2}$ & 290574 & 103478 & 82676 & 242704 & 45916 \\
\hline \multirow[t]{6}{*}{2} & $x_{1}$ & 670 & 518 & 228 & 577 & 394 \\
\hline & $x_{2}$ & 7417 & 5293 & 2028 & 5409 & 3476 \\
\hline & $x_{3}$ & 216872 & 70668 & 80158 & 226318 & 91474 \\
\hline & $x_{4}$ & 60 & 80 & 100 & 100 & 100 \\
\hline & $y_{1}$ & 304201 & 78365 & 73500 & 2127552 & 74445 \\
\hline & $y_{2}$ & 297206 & 78182 & 70810 & 211565 & 73455 \\
\hline \multirow[t]{6}{*}{3} & $x_{1}$ & 591 & 834 & 406 & 744 & 344 \\
\hline & $x_{2}$ & 6598 & 8611 & 2702 & 7404 & 3033 \\
\hline & $x_{3}$ & 192924 & 114967 & 106798 & 309790 & 79812 \\
\hline & $x_{4}$ & 60 & 80 & 100 & 100 & 100 \\
\hline & $y_{1}$ & 310701 & 128897 & 101500 & 308246 & 67302 \\
\hline & $y_{2}$ & 305476 & 128615 & 99067 & 306850 & 64389 \\
\hline \multirow[t]{6}{*}{4} & $x_{1}$ & 485 & 584 & 270 & 314 & 210 \\
\hline & $x_{2}$ & 5410 & 5682 & 2412 & 3168 & 1886 \\
\hline & $x_{3}$ & 158188 & 75862 & 95336 & 132553 & 48484 \\
\hline & $x_{4}$ & 60 & 80 & 100 & 100 & 100 \\
\hline & $y_{1}$ & 256454 & 81851 & 95822 & 130751 & 47940 \\
\hline & $y_{2}$ & 250513 & 81681 & 92500 & 130511 & 47195 \\
\hline \multirow[t]{6}{*}{5} & $x_{1}$ & 400 & 594 & 181 & 2651 & 62 \\
\hline & $x_{2}$ & 4461 & 4952 & 1605 & 130505 & 610 \\
\hline & $x_{3}$ & 130439 & 66115 & 63439 & 1109201 & 15682 \\
\hline & $x_{4}$ & 60 & 80 & 100 & 100 & 100 \\
\hline & $y_{1}$ & 219230 & 80996 & 66905 & 95714 & 13221 \\
\hline & $y_{2}$ & 214120 & 80857 & 65000 & 93087 & 13056 \\
\hline
\end{tabular}




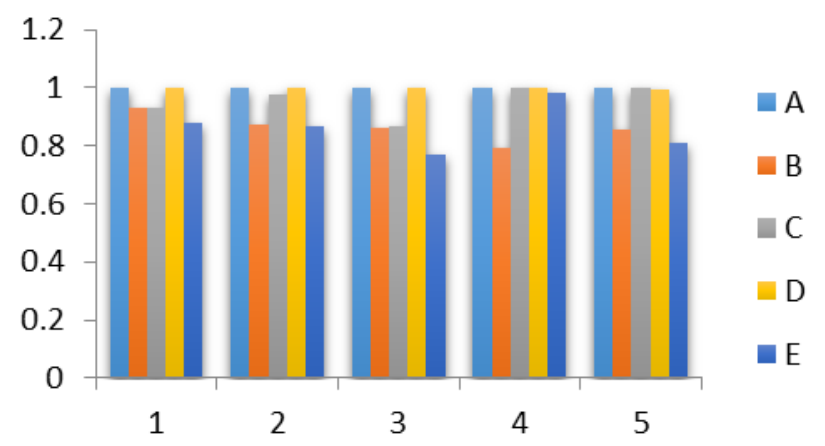

Fig.3 Variation through window stage 1

Figure 1 shows the result in variation through window in determining the efficiency of performance of each production lines. This figure shows the comparison between productions line more clearly. The graph shows that production line $\mathrm{A}$ is excellent in performance with automation usage index 60 . It is then followed by production line $\mathrm{D}$ and production line $\mathrm{C}$ with non-automation. After that is production line $\mathrm{B}$ at fourth place with automation index 80 and non-automation production line $\mathrm{E}$ in fifth place.

\subsection{Stage 2: Evaluation of Quality in Production Lines in Terms of Cost and Time.}

In this stage, we are focusing on losses of quality product due to time and total cost per month use in reaching the targeted productivity. This evaluation will show the company whether their installation of automation brings profit or losses to them. Using the same model of DEA-solver in stage 1, the data was collected and organized by using the result from that stage. By using DEAsolver, Table 2 brings the result from the evaluation. We assumed that the lowest score was facing losses in time and cost.

Table 2 Input and output data to evaluate losses due to time and cost

\begin{tabular}{|c|c|c|c|c|c|c|}
\hline Month & DMU & $\mathrm{A}$ & B & $\mathrm{C}$ & D & $E$ \\
\hline \multirow[t]{4}{*}{1} & $\theta_{2}$ & 1 & 0.859 & 0.802 & 1 & 0.671 \\
\hline & $z_{1}$ & 252 & 587 & 508 & 549 & 558 \\
\hline & $v_{z}$ & 103 & 248 & 232 & 247 & 247 \\
\hline & $z_{2}$ & 100 & 100 & 86.6 & 97.8 & 84.2 \\
\hline \multirow[t]{4}{*}{2} & $\theta_{1}$ & 1 & 0.962 & 0.884 & 1 & 0.718 \\
\hline & $z_{2}$ & 478 & 590 & 532 & 572 & 562 \\
\hline & $v_{z}$ & 205 & 250 & 239 & 253 & 248 \\
\hline & $z_{2}$ & 100 & 100 & 92.3 & 99.5 & 86.9 \\
\hline \multirow[t]{4}{*}{3} & $\theta_{2}$ & 1 & 0.751 & 0.798 & 0.907 & 0.595 \\
\hline & $z_{1}$ & 478 & 583 & 538 & 567 & 489 \\
\hline & $F_{z}$ & 205 & 243 & 241 & 252 & 226 \\
\hline & $z_{2}$ & 100 & 100 & 93.6 & 98.9 & 90.7 \\
\hline \multirow[t]{4}{*}{4} & $\theta_{2}$ & 1 & 0.710 & 0.838 & 0.935 & 0.715 \\
\hline & $F_{1}$ & 473 & 591 & 516 & 594 & 572 \\
\hline & $F_{z}$ & 203 & 251 & 234 & 259 & 251 \\
\hline & $v_{2}$ & 100 & 100 & 94.2 & 99.1 & 92 \\
\hline \multirow[t]{4}{*}{5} & $\theta_{1}$ & 1 & 0.793 & 0.848 & 0.735 & 0.611 \\
\hline & $g_{1}$ & 504 & 593 & 552 & 537 & 594 \\
\hline & $z_{z}$ & 217 & 253 & 245 & 244 & 258 \\
\hline & $z_{2}$ & 100 & 100 & 95.3 & 98.2 & 91.5 \\
\hline
\end{tabular}




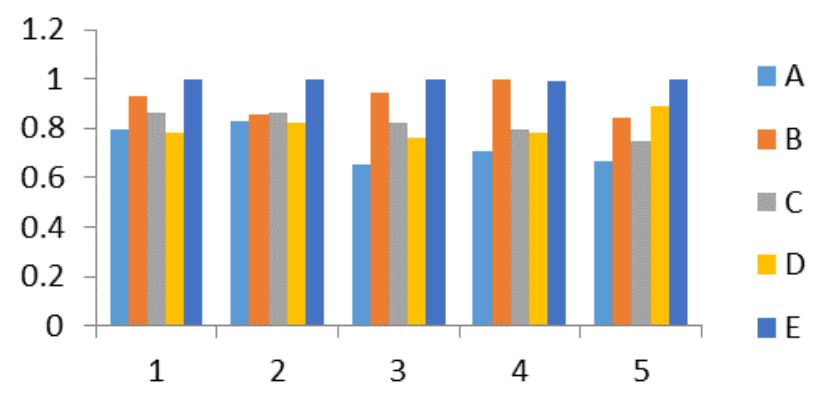

Fig.4 Variation through window stage 2

Figure 5.2 shows the results in variation through window in determining the quality due to losses of time and cost in Production Lines. This figure shows the comparison between productions line more clearly. The graph shows that production line $\mathrm{E}$ is excellent in performance of production line without automation usage. It is then followed by production line $\mathrm{B}$ with automation and production line $\mathrm{C}$ without automation. Production line $\mathrm{D}$ is at the fourth place without automation and production line A with automation is in the fifth place.

The overall results showed that the company is still having the problem after the installation of the automation. Table 3 shows the result for efficiency of productivity, $\theta_{1}$ and quality in terms of time and cost, $\theta_{2}$.

Table 3 Relationship between $\theta_{1}$ and $\theta_{2}$

\begin{tabular}{|l|l|l|}
\hline Production Line & $\boldsymbol{\theta}_{1}$ & $\boldsymbol{\theta}_{2}$ \\
\hline A & 1 & 0.731397 \\
\hline B & 0.861819 & 0.914624 \\
\hline C & 0.954100 & 0.818542 \\
\hline D & 0.998814 & 0.807622 \\
\hline E & 0.860962 & 0.998797 \\
\hline
\end{tabular}

VII. CONCLUSION

As a conclusion, installation of automation does not means it can lead to high quality of product. These results also give us clear point of view about the combination of automation and labour in each production line. On top of that, the company can also know about the improvement that they had done towards their production line and whether it is giving them the advantages or otherwise. In this model, we can observe more clearly the relationship between productivity and the quality of the product.

\section{ACKNOWLEDGEMENT}

The authors acknowledge the Fundamental Research Grant Scheme (FRGS-RDU 13128) received from Ministry of Higher Education Malaysia.

\section{REFERENCES}

[1] Färe, R. and S. Grosskopf , 2000. "Network DEA." Socio-Economic Planning Sciences 34(1): 35-49.

[2] Kaydos, W., Measuring, Managing, and Maximizing Performance Portland, OR: Productivity Press, 1991.

[3] Seiford, L. M. and J. Zhu (1999). "An investigation of returns to scale in data envelopment analysis." Omega 27(1): 1-11. 
[4] Kao C, Hwang S N. Efficiency decomposition in two-stage data envelopment analysis: an application to non-life insurance companies in Taiwan. European Journal of Operational Research 2008; 185: 418-29.

[5] Tone K, Tsut sui M. Network DEA: a slacks-based measure approach. European Journal of Operational Research 2009; 197: 243-52.

[6] Fukuyama, H. and W. L. Weber (2010). "A slacks-based inefficiency measure for a twostage system with bad outputs." Omega 38(5): 398-409.

[7] Kao, C. and S.-N. Hwang (2014). "Multi-period efficiency and Malmquist productivity index in two-stage production systems." European Journal of Operational Research 232(3): 512521

[8] Liang, L., et al. (2008). "Alternative secondary goals in DEA cross-efficiency evaluation." International Journal of Production Economics 113(2): 1025-1030.

[9] Cook, W. D., et al. (2010). "Measuring performance of two-stage network structures by DEA: A review and future perspective." Omega 38(6): 423-430.

[10] Ahmad, Z. and M. Jun (2015). "Agricultural Production Structure Adjustment Scheme Evaluation and Selection Based on DEA Model for Punjab (Pakistan)." Journal of Northeast Agricultural University (English Edition) 22(2): 87-91.

[11] Hartman, T. E. and J. E. Storbeck (1996). "Input congestion in loan operations." International Journal of Production Economics 46-47: 413-421.

[12] Itoh, H., 2002. Efficiency Changes at Major Container Ports in Japan: A window Application of Data Envelopment Analysis. In: Conference. RURDS. The Applied Regional Science Conference, Blackwell, UK, 133-154.

[13] Carbone, T. D., 2000.Measuring Efficiency of Semiconductor Manufacturing Operations Using Data Envelopment Analysis (DEA). In Conference RWS. IEEE/Semi Advanced Semiconductor Manufacturing Conference, Springer, US, 56-62.

[14] Mansor, M. A., 2010. Development of Performance Measurement Methods for Production Maintenance Activities in Manufacturing Systems. pp.4. Phd Dessertations. pp.5. ci.nii.ac.jp/naid/500000538666/?1=en. 